\title{
REASONS FOR SEEKING DENTAL TREATMENT FOLLOWING TRAUMA TO ANTERIOR TEETH AMONG ADULTS IN A LOW- INCOME ECONOMY
}

Enabulele JE, Ibhawoh $\mathbf{L} \mathbf{O}$

Department of Restorative Dentistry, University of Benin, Benin City, Edo State, Nigeria.

Correspondence: Enabulele Joan

P.O.Box 10427, Ugbowo, Benin City, Edo State, Nigeria.

Tel: +2348050731199 Email: jobelladonna10@yahoo.com

\section{ABSTRACT}

Background: Anterior teeth which primarily are the incisors and canine teeth contribute significantly to a satisfactory smile and human appearance. However, they are more likely to be traumatized when trauma is experienced in the facial region. Patient may seek dental attention or treatment immediately or much later due to a variety of reasons including pain, sensitivity, tooth mobility and aesthetic considerations due to tooth substance loss and/or discoloration.

Objective: To review the reasons for seeking dental treatment following trauma to anterior teeth from subjects' perspective and the time of presentation and the distribution patterns of the above.

Materials and Methods: This was a retrospective study of all adult patients who presented with trauma to the anterior teeth between June 2010 and December 2012 at the University of Benin Teaching Hospital, Benin City, Edo State. Simple descriptive analysis was used to characterize the subjects' demographic characteristics, history of the trauma, time elapsed between trauma and presentation and reasons for seeking treatment.

Results and conclusion: There were 221 cases of trauma to the anterior teeth giving an average of 7.34 cases presenting per month. Subjects' ages ranged from $17-69$ years with a mean of $29.7 \pm 11.0$ years. About half of the subjects $(48.4 \%)$ sought treatment for aesthetic concerns (discoloration and disfigured teeth). Pain was the main concern in about one third (35.3\%) of the subjects. Over one third of the subjects presented within the first month of injury, while almost half of the subjects (49.7\%) presented within the first year. The mean time elapsed between injury and presentation among the subjects was $6.84 \pm 8$.5years. There was statistically significant association between time elapsed and the reasons for seeking treatment. Aesthetic consideration was found to be the most common reason for seeking treatment, health education efforts should be include awareness tips on the need for timely response in seeking dental intervention following trauma to the anterior teeth.

Keywords: Trauma, anterior teeth, dental treatment.

\section{INTRODUCTION}

$\mathrm{T}$ he anterior teeth play a vital role in imparting a pleasant human facial appearance. The symmetry in normal human dentition makes abnormalities very conspicuous even to the untrained eyes. The anterior teeth are important both functionally and aesthetically; trauma to one or more of these teeth may have psychological effect on the individual. ${ }^{1}$ Traumatic dental injury is a neglected oral condition despite its relatively high prevalence. ${ }^{2}$ Its nature, substantial impact on the patient's quality of life and the availability of knowledge of its a e t i o l o g y, prevention and treatment make traumatized anterior teeth a potential public health problem. $^{3}$

In some societies, traumatized anterior teeth are not taken seriously and those who sustain dental trauma do not seek care until they develop complications or acute symptoms. ${ }^{4}$ In Nigeria, a very low level of treatment was observed among children. ${ }^{5-7}$ Falomo $^{5}$ reported that $0.7 \%$ of the school children in lbadan with traumatized anterior teeth had received treatment. A study by
Otuyemi and Sofowora ${ }^{6}$ and another by Ajayi et al $^{7}$ reported that none of the traumatized teeth in children had been treated. This unmet treatment need could manifest with complications in adulthood thus becoming a challenging clinical situation.

Time of presentation may 
significantly affect treatment options and their complexities or prognosis. Subjects with traumatized anterior teeth may present either immediately, soon after the trauma or much later. Ajayi et $\mathrm{al}^{7}$ reported an average time interval of about $3.5 y e a r s$ between trauma and dental examination. Traumatized anterior teeth may lead to eating restrictions, changes in physical appearance, speech defects and psychological impacts that affect the patient's quality of life. ${ }^{8}$

Garcia Godoy et $\mathrm{al}^{9}$ reported aesthetic or clinical symptoms, such as pain and swelling as the common reasons for seeking treatment after dental injury. In a Brazilian population, aesthetic reason was found to be slightly more frequent than clinical symptoms. ${ }^{10}$ The main complaint presented in a Jordanian study was pain or sensitivity $(31.3 \%){ }^{11}$ These countries have better economies than Nigeria. It is pertinent therefore that reasons for utilization of dental treatment following trauma to anterior teeth in a low income economy like Nigeria be evaluated.

This study was designed therefore to identify reasons for seeking treatment following trauma to anterior teeth from subjects' perspective, the time of presentation and the distribution patterns of the above in a low income economy.

\section{MATERIALS AND METHODS}

This was a retrospective study of all adult patients who presented with trauma to the anterior teeth from June 2010 to December 2012 at the University of Benin Teaching Hospital, Benin City, Edo State. All consecutive adult patients' case notes with trauma to the anterior teeth were included in the study. All relevant information for the study was obtained from the case notes of the patients so identified. The information extracted were; demographic characteristics, (age, sex, occupation, and marital status), history of the trauma, time elapsed between trauma and presentation and reasons for seeking treatment. All the case notes retrieved had the full information required for the study giving a $100 \%$ retrieval rate.

The data collected were analyzed using the Statistical Package for Social Science (SPSS) version 17.0. For the purpose of analysis the occupations were classified into 4 social classes according to Famuyiwa and Olorunsogo's ${ }^{12}$ classification. The data were subjected to descriptive analysis in the form of frequencies, cross tabulations, mean and standard deviation. Non parametric analysis in the form of chi square was carried out to test for statistical significance with $P$ value $<0.05$ considered statistically significant. The results were presented in the forms of frequencies, percentages, means, standard deviation, bar chart, tables and cross tabulations. The percentages were rounded up to two decimal places.

\section{RESULTS}

A total of 221 cases of trauma to the anterior teeth in adults were seen over the 30 months period giving an average of 7.34 cases per month. Subjects' ages ranged from 17- 69 years with a mean of $29.69 \pm 11.0$ years. The peak age incidence was 21-30 years with a male: female ratio of $1: 1.07$. Majority of the subjects were single $(71.0 \%)$ with $95.0 \%$ being Christians. A majority 120 (54.3\%) of the subjects belonged to the social class III comprising predominantly students (Table $1)$.

About half of the subjects (48.4\%) sought treatment for a esthetic concerns (discoloration and alteration in tooth shape). Pain was the main concern in about one third $(35.3 \%)$ of the subjects. (Figure 1)

Aesthetic concern was the major reason for seeking treatment among subjects aged 50 years and below while pain was the major reason for those greater than 50 years of age. Also females reported aesthetic concerns more often than males while pain was the prevalent reason for seeking treatment in males. Aesthetic concern and pain were the most common reasons for seeking treatment among single and married subjects respectively. There was no significant association between age, gender, marital status and reasons for seeking treatment from patient's perspective. (Table 2)

In all the social classes, aesthetic concern was the commonest reason for seeking treatment. There was no significant association between social class and reason for seeking treatment from the subject's perspective. 
Figure 2 shows the time interval between injury and presentation with close to half of the subjects $(49.7 \%)$ presenting within the first year. The mean time elapsed between injury and presentation among the subjects was $6.42 \pm 8.5$ years.

All subjects with mobile teeth, $83.3 \%$ of subjects with shocking sensation and $50 \%$ of the subjects with pain presented within one month of the traumatic incident. A significant majority $(78.6 \%)$ of subjects with swelling and $90.9 \%$ of those with discoloration presented within 6 and 36years following the traumatic incident (Table 3). There was statistically significant association between time elapsed and the reasons for seeking treatment $(p<0.05)$.

\section{DISCUSSION}

Two hundred and twenty-one cases of trauma to the anterior teeth were seen over the period of the study. There was a male preponderance which was also reported in a previous Nigerian study. ${ }^{13}$ This can be attributed to the fact that there is a general tendency for the male gender to engage in more physical activities and higher risk taking behaviour compared with females.

Aesthetic concern ( discoloration and alteration in tooth shape) was the most common reason for seeking treatment among the subjects thereby corroborating the findings of Leroy et al ${ }^{14}$ while contrasting with Al-Jundi's findings where pain or sensitivity were the main complaints ${ }^{11}$. Despite the fact that Nigeria is a low income economy, Nigerians are still bordered about their appearance demonstrating that appearance is not necessarily a function of the economy. Pain $(35.3 \%)$ was the second most common reason for seeking treatment among the subjects in this study followed by swelling, shocking sensation, tooth mobility and pus discharge. This can be explained by the fact that most subjects were aged 21-

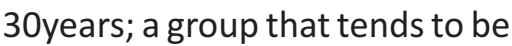
more conscious of their appearances during social interactions and eligibility for marriage. Unlike the single and younger age groups, subjects aged $51-60$ years and those that were married presented mostly with complaints of pain. The older and married subjects were possibly less concerned about their appearance but more concerned about function and the absence of pain.

Similarly, subjects in social class IV (unskilled workers) presented chiefly with the complaint of pain unlike those in social class III (including students) who presented with discoloration and alteration in tooth shape mainly. This is probably a reflection of their level of enlightenment. Subjects with some skills are more enlightened and more likely to demonstrate a better health seeking behaviour.

Unlike males, the main reason for seeking treatment in the female subjects was aesthetic concern. Although no significant association was found between gender and the reason for seeking treatment, there is greater social pressure on women to be physically attractive $^{15}$
The average time elapsed between injury and presentation among the subjects was 6.42 \pm 8.5 years. The absence of discomfort is thought to reflect good oral health and pain arising in the mouth is seen as a warning which does not automatically translate to seeking treatment to regain oral health. ${ }^{16}$ This is in contrast to a study by Ajayi et al ${ }^{7}$ that reported an average time lapse of about 3.5years between trauma and dental examination. This difference can be accounted for in the type of population studied. In the study by Ajayi et al 7 the study population was secondary school students and the study was carried out in the school whereas the present study is hospital based and in adults.

The average time interval between injury and presentation of 6.42 years, in this study may be explained by the early resolution of initial pain or sensitivity without treatment following enamel dentine fractures. Later development of additional symptoms such as swelling from abscess formation, tooth mobility and discoloration may be sequelae of untreated associated pulp disease.

There was a statistically significant association between the time elapsed and the reasons for seeking treatment. $A$ majority of subjects who presented with swelling and/or discoloration presented between 6 and 36years after the traumatic incident showing that these reasons for seeking treatment are time dependent and are associated with possible 
complications such as symptoms associated with pulp necrosis.

\section{CONCLUSION}

Though aesthetic consideration was found to be the most common reason among the subjects in this study, this seemed more important to the females especially those who were in the age bracket of 21$30 y e a r s$. Therefore, awareness level may play an important role in determining presentation to seek dental care for trauma to anterior teeth and thus health education efforts should include awareness tips on the causes, prevention and need for timely responses by the populace in seeking dental intervention in the interest of overall dental and general well being.

\section{REFERENCES}

1) Adekoya-Sofowora C, Sote E, Odusanya S, Fagade $\mathrm{O}$. Traumatic dental injuries of anterior teeth of children in Ile- Ife, Nigeria. Pediatr Dent 2000;10:33-39.

2) Glendor U, Marcenes W, A $n d r$ e a s e $n$ J O. Classification, epidemiology and aetiology. In: Textbook and colour atlas of traumatic injuries to the teeth, $4^{\text {th }}$ ed. Andreasen JO, Andreasen $F M$, Andersson $L$ eds. Blackwell, Oxford. 2007.p. 217-254.

3) Adekoya-Sofowora CA. Traumatised anterior teeth in children: A review of the literature. Niger J Med 2001; 10:151-157.

4) Saroglu I, Sonmez H. The prevalence of traumatic injuries treated in the pedodontic clinic of Ankara University,Turkey, during 18 months. Dent Traumatol 2002; 18:299-303.

5) Falomo B. Fractured permanent incisors among Nigeria School Children. J Dent Child 1986; 8:119-120.

6) Otuyemi OD, AdekoyaSofowora CA. Traumatic anterior dental injuries in selected rural primary school children in Ile-lfe, Nigeria. Niger Dent J 1991; 10:20-25.

7) Ajayi MD, Denloye O, Abiodun-Solanke IMF. The unmet treatment need of traumatized anterior teeth in selected secondary school children in Ibadan, Nigeria. Dent Traumatol 2010; 26:60-63.

8) Lin $\mathrm{H}$, Naidoo S. Causes and prevalence of traumatic injuries to the permanent incisor of school children aged 10-14years in Maseru, Lesotho. SADJ 2008; 63:154156.

9) Garcia-Godoy F, GarciaGodoy F, Garcia-Godoy FM. Reasons for seeking treatment after traumatic dental injuries. Endo Dent Traumatol 1989; 5:180-181.

10) Al-Nazhan S, Andreasen JO, Al-Bawardi S, Al-Rouq S. Evaluation of the effect of delayed management of traumatised permanent teeth. J Endod 1995; 21:391393.

11) Al-Jundi SH. Type of treatment, prognosis and estimation of time spent to manage dental trauma in late presentation cases at a dental teaching hospital; a I ong itudinal and retrospective study. Dent Traumatol 2004; 20:1-5.

12) Famuyiwa OO, Olurunsola DA. Some family factors in Sickle cell anaemia in Lagos, Nigeria. Nig Med Pract 1998; 35:70-73.

13) Adekoya-Sofowora C, Bruimah R, Ogunbodede E. Traumatic Dental Injuries; Experience in Suburban Nigerian Adolescents. Internet J Dent Sci. 2005; 3:14-17.

14) Leroy RL, Aps JK, Raes FM, Martens LC, De Boerer JA. A multidisciplinary treatment approach to a complicated maxillary dental trauma: a case report. Endod Dent Traumatol 2001; 16:138142.

15) Ronis DL, Lang WP, Farghaly MM, Passow E. Tooth brushing, flossing and preventive dental visits by Detroit-area residents in relation to demographic and socioeconomic factors. J Pub Health Dent 1993; 53:138145.

16) Kawamura $M$, Wright FAC, Sasahara H, Yamasaki Y, Suh $S$, Iwamoto Y. An analytical study on gender differences in self reported oral health care and problems of Japanese employees. J Occup Health 1999; 41:104111. 
Table 1: Demographic characteristics of the subjects

\begin{tabular}{|c|c|c|}
\hline Characteristics & $\begin{array}{c}\text { Frequency } \\
\mathrm{n}\end{array}$ & $\begin{array}{c}\text { Percent } \\
\%\end{array}$ \\
\hline \multicolumn{3}{|l|}{ Age (years) } \\
\hline$<21$ & 27 & 12.2 \\
\hline $21-30$ & 131 & 59.3 \\
\hline $31-40$ & 34 & 15.4 \\
\hline $41-50$ & 8 & 3.6 \\
\hline $51-60$ & 18 & 8.1 \\
\hline $61-70$ & 3 & 1.4 \\
\hline \multicolumn{3}{|l|}{ Gender } \\
\hline Male & 107 & 48.4 \\
\hline Female & 114 & 51.6 \\
\hline \multicolumn{3}{|l|}{ Marital Status } \\
\hline Single & 157 & 71.0 \\
\hline Married & 60 & 27.1 \\
\hline Divorced & 1 & 0.5 \\
\hline Widowed & 3 & 1.4 \\
\hline \multicolumn{3}{|l|}{ Religion } \\
\hline Christian & 210 & 95.0 \\
\hline Muslim & 11 & 5.0 \\
\hline \multicolumn{3}{|l|}{ Social Status } \\
\hline Social Class I & 10 & 4.5 \\
\hline Social Class II & 67 & 30.3 \\
\hline Social Class III & 120 & 54.3 \\
\hline sobval Cla & 24 & 10.9 \\
\hline Total & 221 & 100.0 \\
\hline
\end{tabular}


Table 2: Association between demographics and reason for seeking treatment

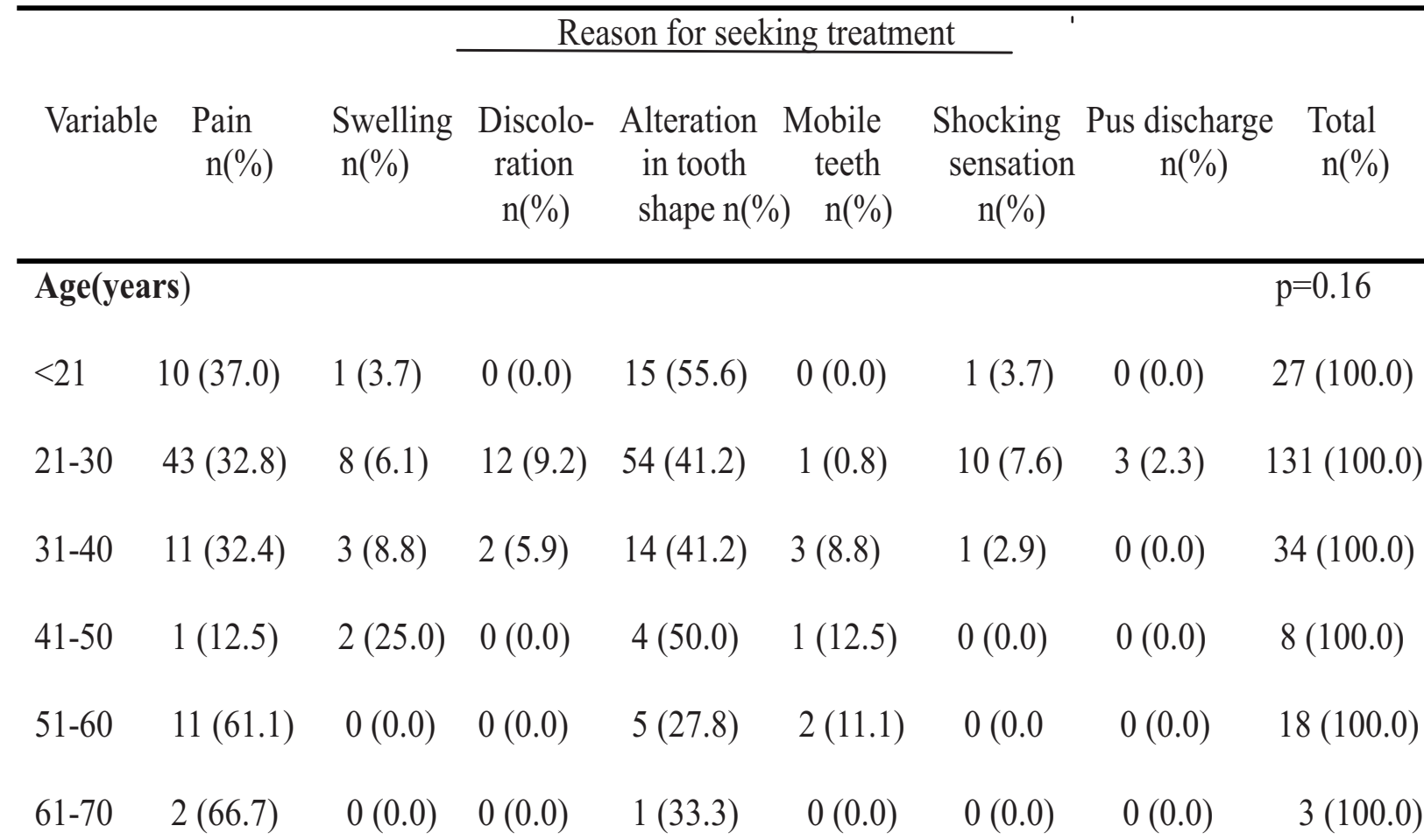

Gender $\mathrm{p}=0.12$

$\begin{array}{lllllll}\text { Male } \quad 48(44.9) & 6(5.6) & 7(6.5) & 37(34.6) & 2(1.9) \quad 5(4.7) & 2(1.9) & 107(100.0)\end{array}$

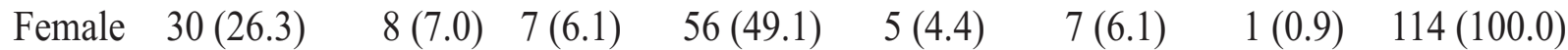

\begin{tabular}{lllllllll}
\hline Marital Status & & & & & & & $\mathrm{p}=0.51$ \\
Single & $50(31.8)$ & $9(5.7)$ & $13(8.3)$ & $71(45.2)$ & $2(1.3)$ & $9(5.7)$ & $3(1.9)$ & $157(100.0)$ \\
Married & $25(41.7)$ & $5(8.3)$ & $1(1.7)$ & $21(35.0)$ & $5(8.3)$ & $3(5.0)$ & $0(0.0)$ & $60(100.0)$ \\
Divorced & $1(100.0)$ & $0(0.0)$ & $0(0.0)$ & $0(0.0)$ & $0(0.0)$ & $0(0.0)$ & $0(0.0)$ & $1(100.0)$ \\
Widowed & $2(66.7)$ & $0(0.0)$ & $0(0.0)$ & $1(33.3)$ & $0(0.0)$ & $0(0.0)$ & $0(0.0)$ & $3(100.0)$
\end{tabular}

Social Class $\mathrm{p}=0.52$

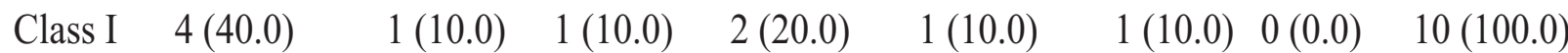

Class II $\quad 22(32.8) \quad 5(7.5) \quad 5(7.5) \quad 26(38.8) \quad 4(6.0) \quad 4(6.0) \quad 1(1.5) \quad 67(100.0)$

Class III $\quad 40(33.3) \quad 8(6.7) \quad 7(45.8) \quad 55(45.8) \quad 1(0.8) \quad 7(5.8) \quad 2(1.7) \quad 120(100.0)$

Class IV $12(50.0) \quad 0(0.0) \quad 1(4.2) \quad 10(41.7) \quad 1(4.2) \quad 0(0.0) \quad 0(0.0) \quad 24(100.0)$ 
Table 3: Relationship between the time elapsed after injury and reason for seeking treatment

\begin{tabular}{|c|c|c|c|c|c|c|c|c|}
\hline \multirow[b]{2}{*}{$\begin{array}{l}\text { Time } \\
\text { elapsed }\end{array}$} & \multirow[b]{2}{*}{$\begin{array}{l}\text { Pain } \\
\mathrm{n}(\%)\end{array}$} & \multirow[b]{2}{*}{$\begin{array}{c}\text { Swelling } \\
\mathrm{n}(\%)\end{array}$} & \multicolumn{3}{|c|}{ Reason for seeking treatment } & \multirow[b]{2}{*}{$\begin{array}{l}\text { Shocking Pus } \\
\text { sensation } \\
\mathrm{n}(\%)\end{array}$} & \multirow[b]{2}{*}{$\begin{array}{c}\text { us discharge } \\
\mathrm{n}(\%)\end{array}$} & \multirow[b]{2}{*}{$\begin{array}{l}\text { Total } \\
\mathrm{n}(\%)\end{array}$} \\
\hline & & & $\begin{array}{cc}\text { Discolo- } & \text { Al } \\
\text { ration } & \text { i } \\
\mathrm{n}(\%) & \mathrm{s}\end{array}$ & $\begin{array}{l}\text { Alteration } M \\
\text { in tooth } \\
\text { shape } \mathrm{n}(\%)\end{array}$ & $\begin{array}{c}\text { Mobile } \\
\text { teeth } \\
\mathrm{n}(\%)\end{array}$ & & & \\
\hline$<1 \mathrm{M}$ & $39(50.0)$ & $1(7.1)$ & $0(0.0)$ & $32(34.4)$ & $7(100.0)$ & $10(83.3)$ & $1(33.3)$ & $90(40.7)$ \\
\hline$>1-3 \mathrm{M}$ & $3(3.8)$ & $0(0.0)$ & $0(0.0)$ & $3(3.2)$ & $0(0.0)$ & $0(0.0)$ & $0(0.0)$ & $6(2.7)$ \\
\hline$>3-6 \mathrm{M}$ & $0(0.0)$ & $2(14.3)$ & $0(0.0)$ & $2(2.2)$ & $0(0.0)$ & $0(0.0)$ & $0(0.0)$ & $4(1.8)$ \\
\hline$>6-12 \mathrm{M}$ & $4(5.1)$ & $0(0.0)$ & $0(0.0)$ & $6(6.5)$ & $0(0.0)$ & $0(0.0)$ & $0(0.0)$ & $10(4.5)$ \\
\hline$>1-3 \mathrm{Y}$ & $5(6.4)$ & $0(0.0)$ & $2(14.3)$ & $4(4.3)$ & $0(0.0)$ & $0(0.0)$ & $0(0.0)$ & $11(5.0)$ \\
\hline$>3-6 \mathrm{Y}$ & $4(5.1)$ & $0(0.0)$ & $2(14.3)$ & $8(8.6)$ & $0(0.0)$ & $0(0.0)$ & $1(33.3)$ & $15(6.8)$ \\
\hline$>6-12 \mathrm{Y}$ & $13(16.7)$ & $2(14.3)$ & $6(42.9)$ & $20(21.5)$ & $0(0.0)$ & $1(8.3)$ & $0(0.0)$ & $42(19.0)$ \\
\hline$>12-36 \mathrm{Y}$ & $9(11.5)$ & $9(64.3)$ & $4(28.6)$ & $18(19.4)$ & $0(0.0)$ & $1(8.3)$ & $1(33.3)$ & $42(19.0)$ \\
\hline$>36 \mathrm{Y}$ & $1(1.3)$ & $0(0.0)$ & $0(0.0)$ & $0(0.0)$ & $0(0.0)$ & $0(0.0)$ & $0(0.0)$ & $1(0.5)$ \\
\hline Total & $78(100.0)$ & ) $14(100.0)$ & 0) $14(100.0)$ & 0) $93(100.0)$ & $7(100.0)$ & $12(100.0)$ & $3(100.0)$ & $221(100.0)$ \\
\hline
\end{tabular}

Figure 1: Subjects' reasons for seeking treatment

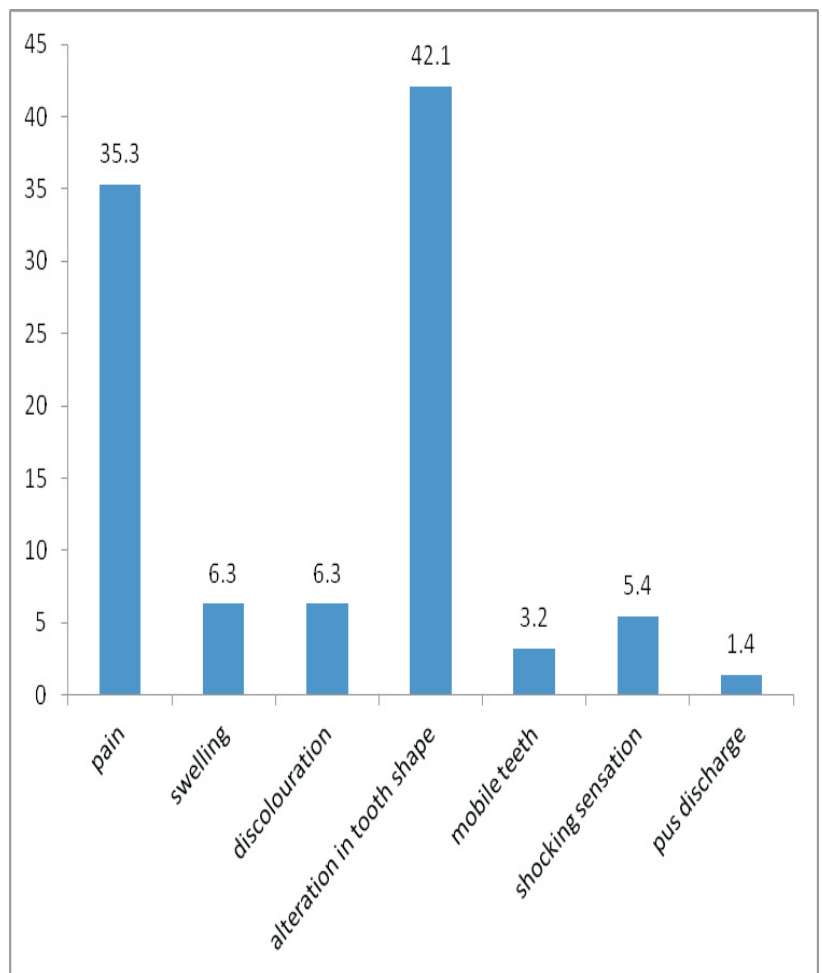

Figure 2: The time interval between injury and presentation

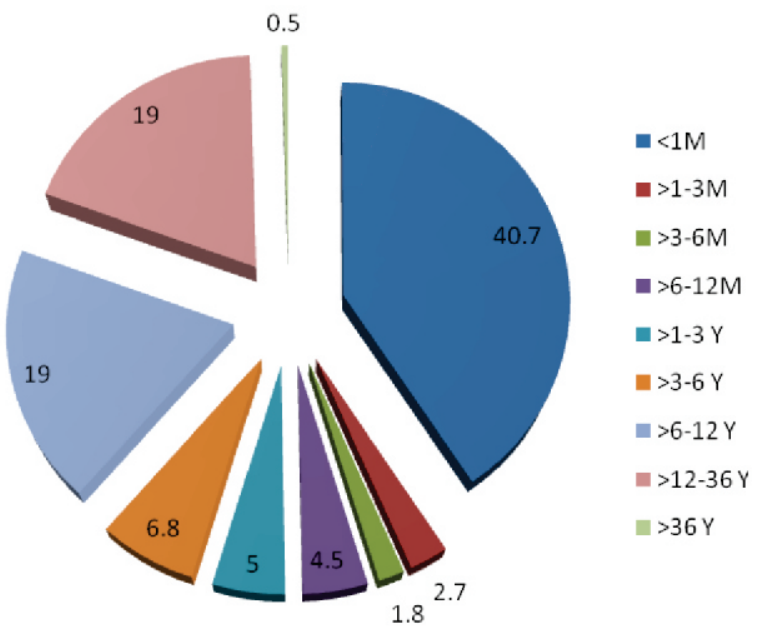

